\title{
Computer-aided analysis of middle cerebral artery tortuosity: association with aneurysm development
}

\author{
Kornelia M. Kliś, ${ }^{1,2}$ Roger M. Krzyżewski, MD, ${ }^{3}$ Borys M. Kwinta, MD, PhD, ${ }^{3}$ \\ Krzysztof Stachura, MD, PhD, ${ }^{3}$ Marek Moskała, MD, PhD, ${ }^{3}$ and \\ Krzysztof A. Tomaszewski, MD, PhD ${ }^{4,5}$
}

\begin{abstract}
${ }^{1}$ Jagiellonian University Medical College, Faculty of Medicine; ${ }^{2} \mathrm{AGH}$ University of Science and Technology, Faculty of Computer Science, Electronics and Telecommunications; ${ }^{3}$ Department of Neurosurgery and Neurotraumatology, Jagiellonian University Medical College; ${ }^{4}$ Department of Anatomy, Jagiellonian University Medical College; and ${ }^{5}$ The Brain and Spine Laboratory, Faculty of Medicine, Jagiellonian University Medical College, Kraków, Poland
\end{abstract}

OBJECTIVE Blood vessel tortuosity may play an important role in the development of vessel abnormalities such as aneurysms. Currently, however, there are no studies analyzing the impact of brain blood vessel tortuosity on the risk of aneurysm formation. Therefore, the authors performed a computer-aided analysis of middle cerebral artery (MCA) tortuosity, especially among patients diagnosed with MCA aneurysms.

METHODS Anatomy of the MCAs of 54 patients with unruptured MCA aneurysms was retrospectively analyzed, as was that of 54 sex-, age-, and vessel side-matched control patients without MCA aneurysms. From medical records, the authors obtained each patient's medical history including previous and current diseases and medications. For each patient, they calculated the following tortuosity descriptors: relative length (RL), sum of angle metrics (SOAM), triangular index (TI), product of angle distance (PAD), and inflection count metric (ICM).

RESULTS Patients with an MCA aneurysm had significantly lower RLs $(0.75 \pm 0.09$ vs $0.83 \pm 0.08, p<0.01)$, SOAMs $(0.45 \pm 0.10$ vs $0.60 \pm 0.17, p<0.01)$, and PADs $(0.34 \pm 0.09$ vs $0.50 \pm 0.17, p<0.01)$. They also had significantly higher TIs $(0.87 \pm 0.04$ vs $0.81 \pm 0.07, p<0.01)$ and ICMs $(3.07 \pm 1.58$ vs $2.26 \pm 1.12, p<0.01)$. Female patients had significantly higher RLs $(0.76 \pm 0.11$ vs $0.80 \pm 0.09, p=0.03)$ than male patients.

CONCLUSIONS Middle cerebral artery aneurysm formation is strongly associated with blood vessel tortuosity parameters, which can potentially be used to screen for patients at risk for MCA aneurysm formation.

https://thejns.org/doi/abs/10.3171/2017.12.JNS172114

KEYWORDS intracranial aneurysm; middle cerebral artery; tortuosity; vascular disorders

$\mathrm{B}$ LOOD vessel tortuosity is a widely observed angiographic finding, which has been reported in terms of veins and arteries in many different locations. ${ }^{11,38,40,48}$ It can affect large vessels,,$^{42,43}$ but it has also been observed in arterioles and venules. ${ }^{3,33}$ Many researchers have proved that tortuosity may be associated with a wide range of vascular abnormalities, especially in terms of retinal and coronary vessels. . $^{87,36}$ It can also be associated with systemic diseases, such as arterial hypertension and diabetes. ${ }^{18,30}$ In addition, it increases with age. ${ }^{1,42}$ One of the explanations for those associations may be the fact that tortuosity results from the mechanical factors of blood flow. Besides its relationship to elevated blood pressure, ${ }^{18}$ tortuosity is also associated with reduced axial tension and artery elongation. ${ }^{15}$ Another explanation may be the weakening of arterial walls, which can result from either elastin degradation $^{12}$ or abnormal deposits within vessel walls. ${ }^{22}$ Also, degradation of surrounding tissue can lead to tortuosity of a vessel. ${ }^{32}$

Many methods of tortuosity analysis have been pro-

ABBREVIATIONS DSA = digital subtraction angiography; $I C M=$ inflection count metrics; $M C A=$ middle cerebral artery; $P A D=$ product of angle distance; $\mathrm{RL}=$ relative length; $S O A M=$ sum of angle metrics; $\mathrm{TI}=$ triangular index.

SUBMITTED August 26, 2017. ACCEPTED December 4, 2017.

INCLUDE WHEN CITING Published online May 18, 2018; DOI: 10.3171/2017.12.JNS172114. 
posed, in both two and three dimensions. ${ }^{4,28}$ Currently, especially in terms of retinal vessels, most analysis is being performed automatically ${ }^{26,39}$ based on angiography or MR angiography, ${ }^{7,14}$

In terms of cerebral vessels, tortuosity has been reported in basilar, middle, posterior, anterior, posterior communicating, and internal carotid arteries. ${ }^{15}$ It can also affect white matter arterioles. ${ }^{44}$ It has been linked with age, hypertension, and moyamoya disease. ${ }^{35,41}$ Tortuosity has also been analyzed in brain tumor vasculature as a potential indicator of tumor malignancy. ${ }^{5}$ Increased tortuosity of the middle cerebral artery (MCA) has been suggested to be associated with MCA atherosclerosis. ${ }^{20}$ To the best of our knowledge, however, there are no studies analyzing the impact of brain blood vessel tortuosity on the risk of aneurysm formation. Therefore, we performed a computer-aided analysis of MCA tortuosity, especially among patients diagnosed with MCA aneurysms, to elucidate whether MCA tortuosity may play an important role in aneurysm formation.

\section{Methods \\ Patients}

We retrospectively analyzed the data of patients with unruptured intracranial aneurysms, confirmed by digital subtraction angiography (DSA), who were hospitalized between January 2013 and March 2017. Patients who underwent aneurysm clipping or coiling were excluded from our study. We selected 54 patients with MCA aneurysms. The control group consisted of 54 patients without MCA aneurysm who were matched for sex, age ( \pm 2 years), and side of MCA. From the medical records, we obtained each patient's medical history including previous and current diseases and medications. The control group consisted of patients undergoing DSA due to suspicion of an intracranial aneurysm based on CT angiography. The study protocol was approved by the local bioethics committee, and all patients gave informed consent.

\section{Software}

To perform all image transformations and factor calculations, we used original software written in C\# 7.0 by the first author of this study utilizing Microsoft Visual Studio Community 2017, licensed for noncommercial use, together with the Emgu CV image processing library.

\section{Image Processing}

To detect the course of the MCA, we performed a series of image transformations on the frontal projection of each patient's DSA study. First, the bone structures were subtracted and image colors were reversed. Then we equalized the histogram to increase image contrast. Finally, images were binarized using an adaptive threshold to extract the image of the internal carotid artery, MCA, and anterior cerebral artery courses. Image binarization allowed us to apply a pathfinding algorithm. We analyzed the $\mathrm{M}_{1}, \mathrm{M}_{2}$, and $\mathrm{M}_{3}$ segments. From the processed image, we automatically extracted the aforementioned segments by selecting the start and end points. To track the vessel course, we used the $A^{*}$ algorithm, which is one of the most efficient pathfinding algorithms and guarantees that the shortest path between two points will be found. ${ }^{49}$ The extracted path was transformed to a curve, which was used for further analysis (Fig. 1).

\section{Relative Length}

The first tortuosity descriptor that we used was relative length (RL), which is defined by the following formula: $l / l_{c}$, where $l_{c}$ is the curve length and $l$ is the length of the straight line between the start and end points of the curve (Fig. 2A). The more the curve deviates from straightness, the lower the RL.

\section{Sum of Angle Metrics}

To calculate the sum of angle metrics (SOAM), the curve is divided into subcurves of equal length. Then for each subcurve, we calculate the supplementary of the angle between lines connecting its center and ends. Angles from every subcurve are summed, and the result is normalized by the length of the entire curve, the SOAM:

$$
\frac{\sum_{i=1}^{n}\left(180^{\circ}-\alpha\right)}{l_{c}}
$$

where $\alpha$ indicates measured angles and $n$ is the number of measured angles (Fig. 2B). For a curve that is straighter, angles are smaller and thus the entire SOAM is smaller. This descriptor is also sensitive to local deviations from a straight line.

\section{Product of Angle Distance}

The product of angle distance (PAD) is calculated using the following formula: RL $\times$ SOAM. This descriptor defines both global tortuosity, which is given by RL, and local tortuosity, which is given by the SOAM.

\section{Triangular Index}

To calculate triangular index (TI), the curve must again be divided into equal subcurves. Then a triangle is built with vertices on each end of the subcurve and in its middle point. The TI is calculated using the following formula:

$$
\frac{\sum_{i=1}^{n} \frac{a_{i}+b_{i}}{c_{i}}}{n}
$$

where $n$ is the number of subcurves, $a$ and $b$ are triangle sides, and $c$ is the triangle base (Fig. 2C). The TI is smaller for straighter curves.

\section{Inflection Count Metrics}

Inflection point is a point on a curve where it changes from being concave to being convex, or vice versa. ${ }^{20}$ The inflection count metrics (ICM) is defined with the following formula: $\left(n_{I} \times l\right) / l$, where $n_{I}$ is the number of the curve's inflection points, $l_{c}$ is the curve length, and $l$ is the distance between the start and end points of the curve (Fig. 2D). This factor is more sensitive to global curvature than RL and is lower for more straight curves. 


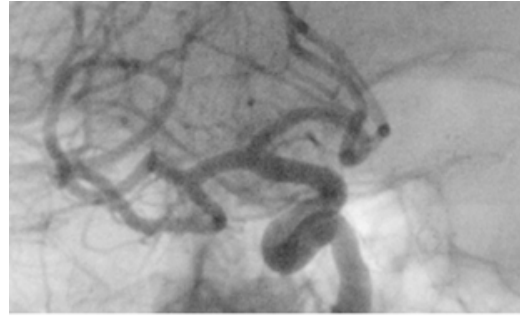

Original image

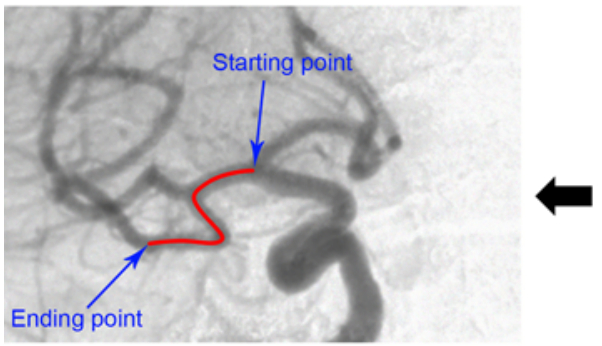

MCA tracking

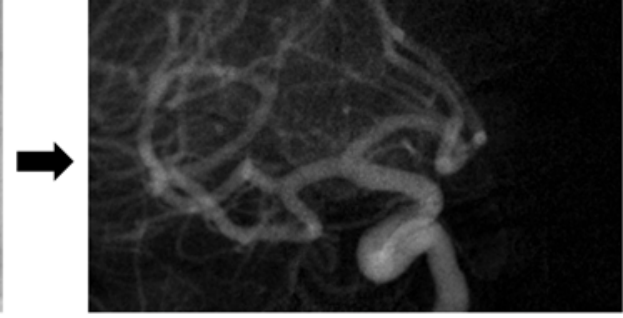

Bone structure subtraction

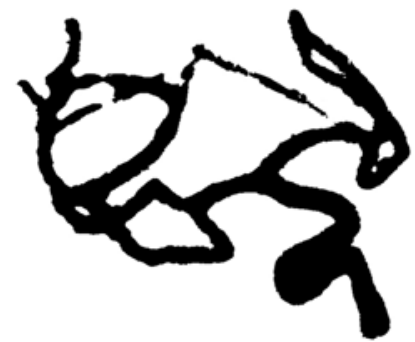

Binarization

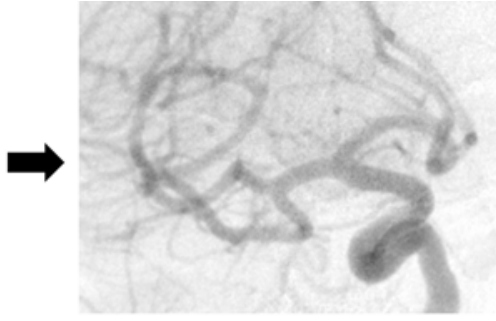

Color inversion

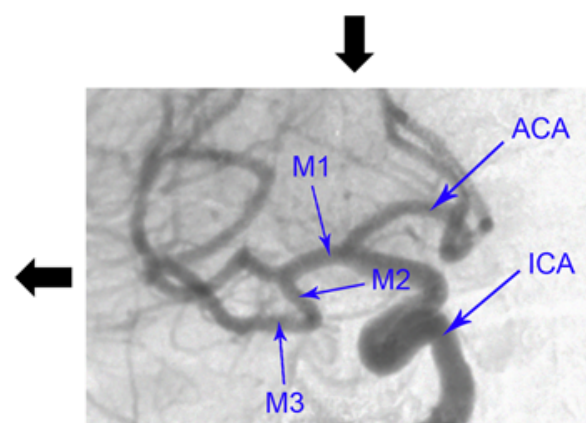

Histogram equalization

FIG. 1. Middle cerebral artery course detection using original software. Bone structures were subtracted and image colors were reversed. Then we equalized the histogram to increase image contrast. Finally, images were binarized using an adaptive threshold to extract the image of the internal carotid artery (ICA), MCA, and anterior cerebral artery (ACA) course. From the processed image, we automatically extracted the $\mathrm{M}_{1}, \mathrm{M}_{2}$, and $\mathrm{M}_{3}$ segments by selecting the start and end points. Figure is available in color online only.

\section{Statistical Analysis}

We used the Shapiro-Wilk test to assess normality. As appropriate for continuous variables, we used the t-test for normally distributed variables and the Mann-Whitney Utest for nonnormally distributed variables. We used the $\chi^{2}$ test for proportional variables. We expressed continuous variables as the mean \pm standard deviation. To find factors independently associated with the presence of an MCA aneurysm, we used multivariate and univariate logistic regression analyses. A $p$ value $<0.05$ was considered to be statistically significant. To perform all statistical analyses, we used Statistica version 10 for Windows (StatSoft Poland).

\section{Results}

We studied 108 patients, and $82(75.93 \%)$ of them were females. Fifty-eight $(53.70 \%)$ analyzed MCAs were located on the right side. Mean age for all patients was $57.64 \pm$ 11.45 years. The mean RL was $0.78 \pm 0.09$, mean SOAM was $0.52 \pm 0.15$, mean PAD was $0.41 \pm 0.15$, mean TI was $0.84 \pm 0.06$, and mean ICM was $2.66 \pm 1.42$. The aneurysm and control groups were fully comparable - the only variables that differed are presented below.

Patients with an MCA aneurysm significantly more often were smokers $(29.63 \%$ vs $9.26 \%, \mathrm{p}=0.01)$, had a history of ischemic heart disease $(7.41 \%$ vs $0 \%, \mathrm{p}=0.04)$, and were treated with $\beta$-blockers $(16.67 \%$ vs $1.85 \%, \mathrm{p}=$ 0.01; Table 1).

Patients with an MCA aneurysm had significantly low- er RLs $(0.75 \pm 0.09$ vs $0.83 \pm 0.08, \mathrm{p}<0.01)$, SOAMs $(0.45$ \pm 0.10 vs $0.60 \pm 0.17, \mathrm{p}<0.01)$, and PADs $(0.34 \pm 0.09$ vs $0.50 \pm 0.17, \mathrm{p}<0.01)$. They also had significantly higher TIs $(0.87 \pm 0.04$ vs $0.81 \pm 0.07, \mathrm{p}<0.01)$ and ICMs $(3.07$ \pm 1.58 vs $2.26 \pm 1.12$, p $<0.01$; Table 1$)$. Female patients had significantly higher RLs $(0.76 \pm 0.11$ vs $0.80 \pm 0.09$, p $=0.03$ ) than male patients (Table 2).

On multivariate logistic regression analysis, after adjustment for possible confounders, smoking (OR 4.12, 95\% CI 1.41-13.96, p < 0.01) and higher ICM (OR 1.54, $95 \%$ CI 1.15-2.12, $\mathrm{p}<0.01)$ remained independently associated with MCA aneurysm occurrence.

\section{Discussion}

Our study showed statistically significant differences in tortuosity descriptors between patients with MCA aneurysms and those without. We found that RLs for patients with an aneurysm were lower and that TIs along with ICMs were higher. On the other hand, SOAMs and PADs were higher for patients without MCA aneurysms. As a lower RL is associated with higher global tortuosity and a higher SOAM is associated with higher local tortuosity, our study results suggest that increased global tortuosity plays a role in MCA aneurysm formation instead of local inflection points. This theory is further confirmed by the fact that a higher ICM was independently associated with a higher risk for MCA aneurysm occurrence, as ICM is higher for curves with more inflection points.

Our findings are consistent with those of Labeyrie et 


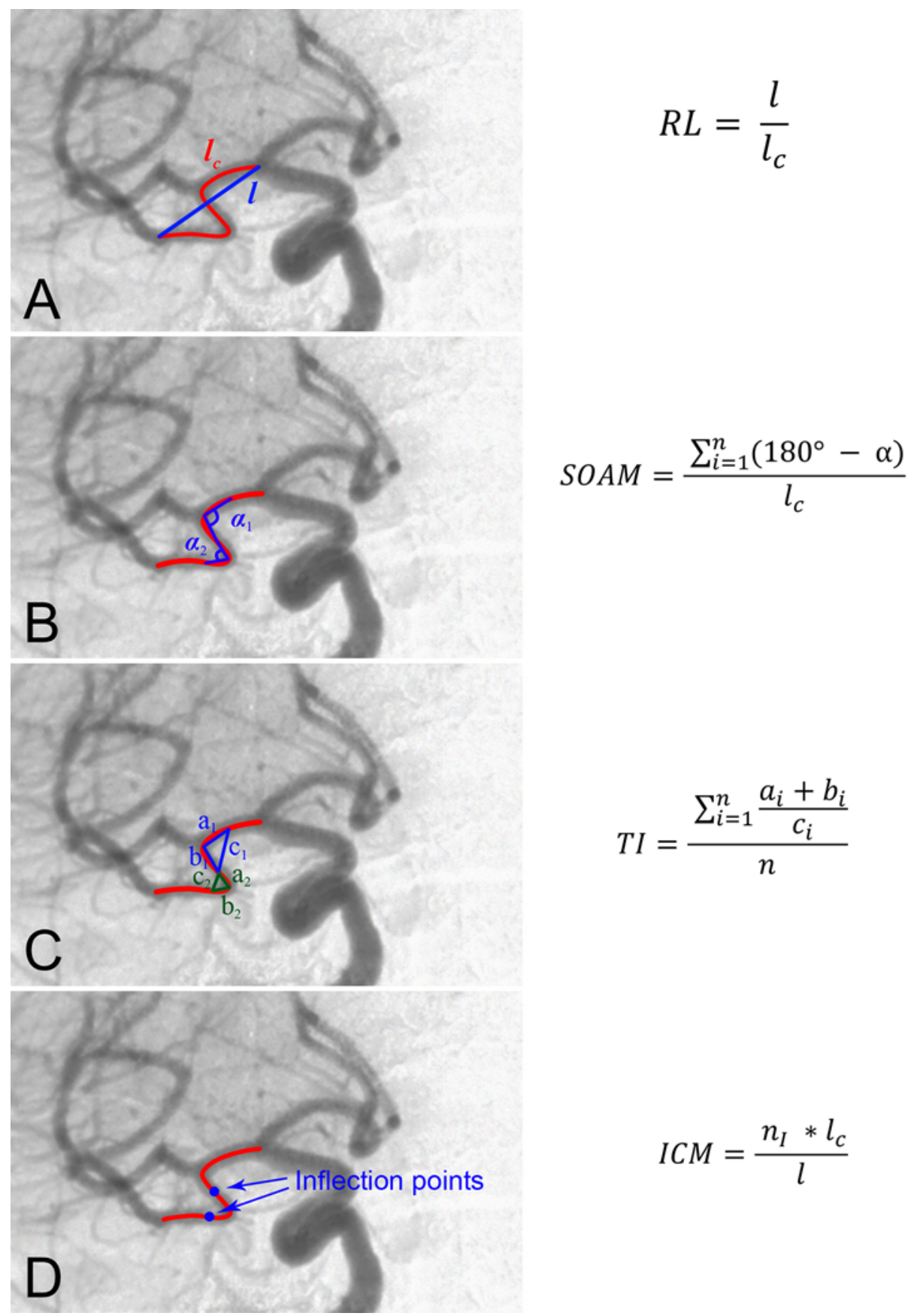

FIG. 2. Illustration of tortuosity descriptor calculations. RL = relative length $(\mathbf{A})$; SOAM = sum of angle metrics, $n=$ number of measured angles, $I_{c}=$ curve length $(\mathbf{B}) ; \mathrm{TI}=$ triangular index, $n=$ number of constructed triangles (C); ICM = inflection count metrics, $n_{l}=$ number of inflection points, $I_{c}=$ curve length, $I=$ distance between start and end points of the curve (D). Figure is available in color online only.

al., who showed that internal carotid artery tortuosity is linked with intracranial aneurysm formation. ${ }^{23}$ However, Labeyrie et al. defined arterial tortuosity as simple elongation in the course of the artery. It can also be defined as two markedly tortuous turns, kinking, or acute angulation of the artery with an angle between the two segments of more than $60^{\circ}$, or coil elongation of the artery resulting in $360^{\circ}$ degrees of rotation. ${ }^{23} \mathrm{An}$ association between tortuosity and aneurysms was also shown in terms of vertebral arteries in the Virgilio et al. study; ${ }^{45}$ however, the association was not further confirmed by the Nasr et al. study. ${ }^{29}$ Tortuosity also plays a role in aortic aneurysm analysis. It was proven to be associated with a higher risk of rupture, ${ }^{25}$ as well as with higher maximum wall stress. ${ }^{31}$ An explanation for the association between higher tortuosity and MCA aneurysm occurrence may be the fact that higher tortuosity is associated with arterial wall weakening. ${ }^{12,15}$ There are a few rare genetic syndromes that are linked to 
TABLE 1. Comparison of risk factors, medications, and MCA tortuosity parameters

\begin{tabular}{|c|c|c|c|}
\hline Parameter & $\begin{array}{c}\text { MCA } \\
\text { Aneurysm }\end{array}$ & $\begin{array}{c}\text { No MCA } \\
\text { Aneurysm }\end{array}$ & $\begin{array}{c}p \\
\text { Value }\end{array}$ \\
\hline No. of patients & 54 & 54 & \\
\hline Female sex & $57.41 \%$ & $51.85 \%$ & 0.56 \\
\hline Rt side & $38.89 \%$ & $48.15 \%$ & 0.33 \\
\hline Age in yrs & $56.83 \pm 11.44$ & $58.44 \pm 11.52$ & 0.47 \\
\hline \multicolumn{4}{|l|}{ Comorbidities } \\
\hline Hypertension & $7.41 \%$ & $16.67 \%$ & 0.14 \\
\hline Smoking & $29.63 \%$ & $9.26 \%$ & 0.01 \\
\hline Diabetes mellitus & $5.56 \%$ & $3.7 \%$ & 0.65 \\
\hline Ischemic heart disease & $7.41 \%$ & $0 \%$ & 0.04 \\
\hline History of heart attack & $7.41 \%$ & $1.85 \%$ & 0.17 \\
\hline History of ischemic stroke & $1.85 \%$ & $3.7 \%$ & 0.56 \\
\hline Atrial fibrillation & $1.85 \%$ & $0 \%$ & 0.32 \\
\hline Lungs diseases & $0 \%$ & $3.7 \%$ & 0.15 \\
\hline Hypothyroidism & $1.85 \%$ & $0 \%$ & 0.32 \\
\hline Hypercholesterolemia & $20.37 \%$ & $16.67 \%$ & 0.62 \\
\hline \multicolumn{4}{|l|}{ Current medications } \\
\hline Acetylsalicylic acid & $25.93 \%$ & $24.07 \%$ & 0.82 \\
\hline$\beta$-blockers & $16.67 \%$ & $1.85 \%$ & 0.01 \\
\hline ACE inhibitors & $1.85 \%$ & $5.56 \%$ & 0.31 \\
\hline Calcium channel blockers & $3.7 \%$ & $1.85 \%$ & 0.56 \\
\hline Diuretics & $5.56 \%$ & $3.7 \%$ & 0.65 \\
\hline Steroids & $0 \%$ & $1.85 \%$ & 0.32 \\
\hline Hypoglycemic agents & $3.7 \%$ & $0 \%$ & 0.15 \\
\hline Insulin & $1.85 \%$ & $7.41 \%$ & 0.17 \\
\hline Statins & $1.85 \%$ & $0 \%$ & 0.32 \\
\hline \multicolumn{4}{|l|}{ Tortuosity descriptor } \\
\hline Relative length & $0.75 \pm 0.09$ & $0.83 \pm 0.08$ & $<0.01$ \\
\hline Sum of angle metrics & $0.45 \pm 0.10$ & $0.60 \pm 0.17$ & $<0.01$ \\
\hline Product of angle distance & $0.34 \pm 0.09$ & $0.50 \pm 0.17$ & $<0.01$ \\
\hline Triangular index & $0.87 \pm 0.04$ & $0.81 \pm 0.07$ & $<0.01$ \\
\hline Inflection count metric & $3.07 \pm 1.58$ & $2.26 \pm 1.12$ & $<0.01$ \\
\hline
\end{tabular}

$\mathrm{ACE}=$ angiotensin-converting enzyme.

Values expressed as the mean \pm standard deviation, unless indicated otherwise.

the presence of vessel tortuosity, such as artery tortuosity syndrome or Loeys-Dietz syndrome. ${ }^{6,21}$ Those syndromes are characterized by impaired arterial wall structure and the formation of aneurysms. ${ }^{13,15,34}$ Another explanation may be found in the study by Kim et al., which showed a correlation between higher MCA tortuosity and a higher risk of atherosclerosis, ${ }^{20}$ just as an association between atherosclerosis and cerebral aneurysm formation had been previously observed. ${ }^{17} \mathrm{Kim}$ et al. found that factors such as hypertension, hyperlipidemia, and smoking are associated with MCA stroke and MCA atherosclerotic disease. ${ }^{20}$ Tortuosity has been associated with certain atherosclerosis hallmarks and risk factors such as intima-media complex. ${ }^{10}$ Femoral artery tortuosity has been associated with higher weight, body mass index, and body surface area. ${ }^{47}$
TABLE 2. Comparison of tortuosity descriptors between female and male patients

\begin{tabular}{lccc}
\hline \multicolumn{1}{c}{ Tortuosity Descriptor } & Female $(n=82)$ & Male $(n=26)$ & $p$ Value \\
\hline Relative length & $0.76 \pm 0.11$ & $0.80 \pm 0.09$ & 0.03 \\
\hline Sum of angle metrics & $0.48 \pm 0.12$ & $0.54 \pm 0.17$ & 0.11 \\
\hline Product of angle distance & $0.37 \pm 0.13$ & $0.43 \pm 0.16$ & 0.07 \\
\hline Triangular index & $0.85 \pm 0.07$ & $0.84 \pm 0.06$ & 0.48 \\
\hline Inflection count metric & $2.46 \pm 1.46$ & $2.72 \pm 1.42$ & 0.42 \\
\hline
\end{tabular}

Values expressed as the mean \pm standard deviation.

Also, the fact that tortuosity can be the result of increased blood flow ${ }^{16}$ and is strongly related to arterial hyperten$\operatorname{sion}^{8,18,33}$ may explain the higher risk of aneurysms in patients with a tortuous MCA.

In terms of a lower SOAM in arteries with an MCA aneurysm, the explanation is most probably connected with fluid dynamics. Artery tortuosity increases the resistance to blood flow. ${ }^{19,37}$ It is also associated with lower wall shear stress and lumen shear stress. ${ }^{24}$ Nippert et al. showed that fluid flow through sharply bent tubes is associated with separation that can cause high-energy loss. ${ }^{48}$ Therefore, blood flow through an artery with larger local angles may cause a local decrease in blood pressure. This also leads to a decrease in local blood flow. Lower blood flow and blood pressure are protective factors against aneurysm formation.

Our study also showed that female patients have lower RLs than male patients. Higher vessel tortuosity among women has been shown in terms of coronary arteries. ${ }^{9,10}$ This fact may be correlated with a higher prevalence of intracranial aneurysms in female patients. ${ }^{46}$ It is also known that female patients are at higher risk for atherosclerosis. ${ }^{2}$

The present study has certain limitations, including the limited size of the study sample. As patients with unruptured MCA aneurysms do not routinely undergo DSA, we were able to obtain only 54 examinations over a period of 4 years. We were able to perform analysis on age-, sex-, and side-matched patients. On the other hand, we were not able to recruit and match patients according to all risk factors. Further analysis should be performed on larger and more varied patient groups. Despite this limitation, this is the first study to analyze MCA tortuosity in terms of aneurysm formation.

\section{Conclusions}

We found that an increased deviation of the MCA from a straight axis (described by RL), a decreased sum of all MCA angles (described by SOAM), a local increase of the MCA angle heterogeneity, and an increase in changes in an artery's course (described by ICM) are associated with MCA aneurysm formation. Smoking and ICM are independently associated with MCA aneurysm formation.

\section{References}

1. Amemiya T, Bhutto IA: Retinal vascular changes and systemic diseases: corrosion cast demonstration. Ital J Anat Embryol 106 (2 Suppl 1):237-244, 2001 
2. Barengolts EI, Berman M, Kukreja SC, Kouznetsova T, Lin C, Chomka EV: Osteoporosis and coronary atherosclerosis in asymptomatic postmenopausal women. Calcif Tissue Int 62:209-213, 1998

3. Batra S, Rakusan K: Capillary length, tortuosity, and spacing in rat myocardium during cardiac cycle. Am J Physiol 263:H1369-H1376, 1992

4. Bullitt E, Gerig G, Pizer SM, Lin W, Aylward SR: Measuring tortuosity of the intracerebral vasculature from MRA images. IEEE Trans Med Imaging 22:1163-1171, 2003

5. Bullitt E, Zeng D, Gerig G, Aylward S, Joshi S, Smith JK, et al: Vessel tortuosity and brain tumor malignancy: a blinded study. Acad Radiol 12:1232-1240, 2005

6. Callewaert BL, Willaert A, Kerstjens-Frederikse WS, De Backer J, Devriendt K, Albrecht B, et al: Arterial tortuosity syndrome: clinical and molecular findings in 12 newly identified families. Hum Mutat 29:150-158, 2008

7. Cheng CP, Wilson NM, Hallett RL, Herfkens RJ, Taylor CA: In vivo MR angiographic quantification of axial and twisting deformations of the superficial femoral artery resulting from maximum hip and knee flexion. J Vasc Interv Radiol 17:979-987, 2006

8. Cheung CY, Zheng Y, Hsu W, Lee ML, Lau QP, Mitchell $\mathrm{P}$, et al: Retinal vascular tortuosity, blood pressure, and cardiovascular risk factors. Ophthalmology 118:812-818, 2011

9. Chiha J, Mitchell P, Gopinath B, Burlutsky G, Kovoor P, Thiagalingam A: Gender differences in the prevalence of coronary artery tortuosity and its association with coronary artery disease. Int J Cardiol Heart Vasc 14:23-27, 2016

10. Davutoglu V, Dogan A, Okumus S, Demir T, Tatar G, Gurler $\mathrm{B}$, et al: Coronary artery tortuosity: comparison with retinal arteries and carotid intima-media thickness. Kardiol Pol 71:1121-1128, 2013

11. Del Corso L, Moruzzo D, Conte B, Agelli M, Romanelli AM, Pastine F, et al: Tortuosity, kinking, and coiling of the carotid artery: expression of atherosclerosis or aging? Angiology 49:361-371, 1998

12. Dobrin PB, Schwarcz TH, Baker WH: Mechanisms of arterial and aneurysmal tortuosity. Surgery 104:568-571, 1988

13. Franceschini P, Guala A, Licata D, Di Cara G, Franceschini D: Arterial tortuosity syndrome. Am J Med Genet 91:141143,2000

14. Grego F, Lepidi S, Cognolato D, Frigatti P, Morelli I, Deriu GP: Rationale of the surgical treatment of carotid kinking. J Cardiovasc Surg (Torino) 44:79-85, 2003

15. Han HC: Twisted blood vessels: symptoms, etiology and biomechanical mechanisms. J Vasc Res 49:185-197, 2012

16. Hoi Y, Gao L, Tremmel M, Paluch RA, Siddiqui AH, Meng $\mathrm{H}$, et al: In vivo assessment of rapid cerebrovascular morphological adaptation following acute blood flow increase. J Neurosurg 109:1141-1147, 2008

17. Hokari M, Isobe M, Imai T, Chiba Y, Iwamoto N, Isu T: The impact of atherosclerotic factors on cerebral aneurysm is location dependent: aneurysms in stroke patients and healthy controls. J Stroke Cerebrovasc Dis 23:2301-2307, 2014

18. Hughes AD, Martinez-Perez E, Jabbar AS, Hassan A, Witt NW, Mistry PD, et al: Quantification of topological changes in retinal vascular architecture in essential and malignant hypertension. J Hypertens 24:889-894, 2006

19. Hutchins GM, Miner MM, Bulkley BH: Tortuosity as an index of the age and diameter increase of coronary collateral vessels in patients after acute myocardial infarction. Am J Cardiol 41:210-215, 1978

20. Kim BJ, Kim SM, Kang DW, Kwon SU, Suh DC, Kim JS: Vascular tortuosity may be related to intracranial artery atherosclerosis. Int J Stroke 10:1081-1086, 2015

21. Kono AK, Higashi M, Morisaki H, Morisaki T, Tsutsumi Y, Akutsu K, et al: High prevalence of vertebral artery tortuos- ity of Loeys-Dietz syndrome in comparison with Marfan syndrome. Jpn J Radiol 28:273-277, 2010

22. Kylstra JA, Wierzbicki T, Wolbarsht ML, Landers MB III, Stefansson E: The relationship between retinal vessel tortuosity, diameter, and transmural pressure. Graefes Arch Clin Exp Ophthalmol 224:477-480, 1986

23. Labeyrie PE, Braud F, Gakuba C, Gaberel T, Orset C, Goulay $\mathrm{R}$, et al: Cervical artery tortuosity is associated with intracranial aneurysm. Int J Stroke 12:549-552, 2017

24. Lee AY: Determining the critical buckling of blood vessels through modeling and in vitro experiments [dissertation]. San Antonio: University of Texas at San Antonio, 2011

25. Lee KM, Choi SY, Kim MU, Lee DY, Kim KA, Park S: Effects of anatomical characteristics as factors in abdominal aortic aneurysm rupture: CT aortography analysis. Medicine (Baltimore) 96:e7236, 2017

26. Li X, Wee WG: Retinal vessel detection and measurement for computer-aided medical diagnosis. J Digit Imaging 27:120132, 2014

27. Li Y, Shen C, Ji Y, Feng Y, Ma G, Liu N: Clinical implication of coronary tortuosity in patients with coronary artery disease. PLoS One 6:e24232, 2011

28. Makkapati VV, Ravi VVC: Computation of tortuosity of two dimensional vessels, in 2015 Eighth International Conference on Advances in Pattern Recognition (ICAPR). Piscataway, NJ: IEEE, 2015

29. Nasr DM, Brinjikji W, Rouchaud A, Kadirvel R, Flemming $\mathrm{KD}$, Kallmes DF: Imaging characteristics of growing and ruptured vertebrobasilar non-saccular and dolichoectatic aneurysms. Stroke 47:106-112, 2016

30. Owen CG, Newsom RS, Rudnicka AR, Barman SA, Woodward EG, Ellis TJ: Diabetes and the tortuosity of vessels of the bulbar conjunctiva. Ophthalmology 115:e27-e32, 2008

31. Pérez EA, Rojas-Solórzano LR, Finol E: Geometric predictors of abdominal aortic aneurysm maximum wall stress. Chem Eng Trans 49:73-78, 2016

32. Poni ES, Liwnicz BH, Ying-Ying Y, North M: Tortuosity of terminal arterioles in the basal ganglia is increased in status lacunaris. Invest Clin 44:137-145, 2003

33. Pries AR, Secomb TW: Structural adaptation of microvascular networks and development of hypertension. Microcirculation 9:305-314, 2002

34. Rahme RJ, Adel JG, Bendok BR, Bebawy JF, Gupta DK, Batjer HH: Association of intracranial aneurysm and LoeysDietz syndrome: case illustration, management, and literature review. Neurosurgery 69:E488-E493, 2011

35. Ruan LT, Duan YY, Cao TS, Zhuang L, Huang L: Color and power Doppler sonography of extracranial and intracranial arteries in moyamoya disease. J Clin Ultrasound 34:60-69, 2006

36. Sasongko MB, Wong TY, Nguyen TT, Cheung CY, Shaw JE, Wang JJ: Retinal vascular tortuosity in persons with diabetes and diabetic retinopathy. Diabetologia 54:2409-2416, 2011

37. Schep G, Bender MH, van de Tempel G, Wijn PF, de Vries WR, Eikelboom BC: Detection and treatment of claudication due to functional iliac obstruction in top endurance athletes: a prospective study. Lancet 359:466-473, 2002

38. Schep G, Kaandorp DW, Bender MH, Weerdenburg H, van Engeland S, Wijn PF: Magnetic resonance angiography used to detect kinking in the iliac arteries in endurance athletes with claudication. Physiol Meas 22:475-487, 2001

39. Sodi A, Guarducci M, Vauthier L, Ioannidis AS, Pitz S, Abbruzzese G, et al: Computer assisted evaluation of retinal vessels tortuosity in Fabry disease. Acta Ophthalmol 91:e113e119, 2013

40. Soikkonen K, Wolf J, Mattila K: Tortuosity of the lingual artery and coronary atherosclerosis. Br J Oral Maxillofac Surg 33:309-311, 1995

41. Spangler KM, Challa VR, Moody DM, Bell MA: Arteriolar 
tortuosity of the white matter in aging and hypertension. A microradiographic study. J Neuropathol Exp Neurol 53:2226, 1994

42. Sugawara J, Hayashi K, Yokoi T, Tanaka H: Age-associated elongation of the ascending aorta in adults. JACC Cardiovasc Imaging 1:739-748, 2008

43. Thomas JB, Antiga L, Che SL, Milner JS, Steinman DA, Spence JD, et al: Variation in the carotid bifurcation geometry of young versus older adults: implications for geometric risk of atherosclerosis. Stroke 36:2450-2456, 2005

44. Thore CR, Anstrom JA, Moody DM, Challa VR, Marion MC, Brown WR: Morphometric analysis of arteriolar tortuosity in human cerebral white matter of preterm, young, and aged subjects. J Neuropathol Exp Neurol 66:337-345, 2007

45. Virgilio F, Maurel B, Davis M, Hamilton G, Mastracci TM: Vertebral tortuosity index in patients with non-connective tissue disorder-related aneurysm disease. Eur J Vasc Endovasc Surg 53:425-430, 2017

46. Vlak MH, Algra A, Brandenburg R, Rinkel GJ: Prevalence of unruptured intracranial aneurysms, with emphasis on sex, age, comorbidity, country, and time period: a systematic review and meta-analysis. Lancet Neurol 10:626-636, 2011

47. Wood NB, Zhao SZ, Zambanini A, Jackson M, Gedroyc W, Thom SA, et al: Curvature and tortuosity of the superficial femoral artery: a possible risk factor for peripheral arterial disease. J Appl Physiol (1985) 101:1412-1418, 2006

48. Zegers ES, Meursing BT, Zegers EB, Oude Ophuis AJ:
Coronary tortuosity: a long and winding road. Neth Heart J 15:191-195, 2007

49. Zeng W, Church RL: Finding shortest paths on real road networks: the case for A*. Int J Geogr Inf Sci 23:531-543, 2009

\section{Disclosures}

The authors report no conflict of interest concerning the materials or methods used in this study or the findings specified in this paper.

\section{Author Contributions}

Conception and design: Krzyżewski, Kliś. Acquisition of data: Krzyżewski, Kliś. Analysis and interpretation of data: Krzyżewski, Kliś, Tomaszewski. Drafting the article: Kliś, Kwinta, Stachura, Moskała. Critically revising the article: Kliś, Kwinta, Stachura, Moskała, Tomaszewski. Reviewed submitted version of manuscript: Krzyżewski, Kliś, Tomaszewski. Approved the final version of the manuscript on behalf of all authors: Krzyżewski. Statistical analysis: Kliś.

\section{Correspondence}

Roger M. Krzyżewski: Jagiellonian University Medical College, Kraków, Poland.roger.krzyzewski@gmail.com. 